\title{
SCIENTIFIC REPORTS

\section{OPEN A tiny new Middle Triassic stem- lepidosauromorph from Germany: implications for the early evolution of lepidosauromorphs and the Vellberg fauna}

\author{
Gabriela Sobral $^{1 *}$, Tiago R. Simões ${ }^{2} \&$ Rainer R. Schoch ${ }^{1}$
}

The Middle Triassic was a time of major changes in tetrapod faunas worldwide, but the fossil record for this interval is largely obscure for terrestrial faunas. This poses a severe limitation to our understanding on the earliest stages of diversification of lineages representing some of the most diverse faunas in the world today, such as lepidosauromorphs (e.g., lizards and tuataras). Here, we report a tiny new lepidosauromorph from the Middle Triassic from Vellberg (Germany), which combines a mosaic of features from both early evolving squamates and rhynchocephalians, such as the simultaneous occurrence of a splenial bone and partial development of acrodonty. Phylogenetic analyses applying different optimality criteria, and combined morphological and molecular data, consistently recover the new taxon as a stem-lepidosauromorph, implying stem-lepidosauromorph species coinhabited areas comprising today's central Europe at the same time as the earliest known rhynchocephalians and squamates. It further demonstrates a more complex evolutionary scenario for dental evolution in early lepidosauromorphs, with independent acquisitions of acrodonty early in their evolutionary history. The small size of most terrestrial vertebrates from Vellberg is conspicuous, contrasting to younger Triassic deposits worldwide, but comparable to Early Triassic faunas, suggesting a potential long-lasting Lilliput effect in this fauna.

The Middle Triassic was a time of major changes in terrestrial tetrapod faunas on a global scale. Despite the most recent divergence time estimates based on molecular and morphological data indicating the origin of most diapsid lineages during the Permian ${ }^{1,2}$, several lineages of diapsids are recognized in the fossil record for the first time only in the Middle Triassic, such as squamates, rhynchocephalians, tanystropheids, and drepanosaurs ${ }^{2-4}$. Other lineages that first appeared in the fossil record in the Early Triassic or Late Permian considerably increase in abundance and taxonomic representation during the Middle Triassic, such as ichthyosauromorphs, sauropterygians, and turtles ${ }^{5-7}$. Additionally, there is a generally poor vertebrate fossil record for the Early Triassic, partially owing to the relatively long period of recovery from the Permian-Triassic mass extinction ${ }^{8,9}$. All of those factors combined make the Middle Triassic of fundamental importance to understand the recovery of global faunas after the greatest mass extinction of the Phanerozoic, and the initial diversification of characteristic components of the modern vertebrae biota, such as archosauromorph and lepidosauromorph reptiles.

Among the tetrapod lineages that began diversifying in the fossil record at least by the Middle Triassic, lepidosauromorphs are one of the most diverse, representing one of the largest lineages of diapsid reptiles today (alongside birds), with ca. 10,500 described species ${ }^{10,11}$. The earliest putative stem-lepidosauromorphs first appear in the fossil record in the Late Permian-e.g. Palaeagama ${ }^{12,13}$ - whereas crown lepidosauromorphs are first recognized in the Middle Triassic, represented by the oldest known squamate ${ }^{2}$ and rhynchocephalians ${ }^{14,15}$. However, the Triassic record of lepidosauromorphs is, in general, still extremely poor when compared to other lineages of diapsid reptiles ${ }^{4-7}$. Currently, only a few Triassic localities provide diagnostic lepidosauromorph taxa, including:

\footnotetext{
${ }^{1}$ Staatliches Museum für Naturkunde Stuttgart, Rosenstein 1, D-70191, Stuttgart, Germany. ${ }^{2}$ Department of Organismic and Evolutionary Biology, Museum of Comparative Zoology, Harvard University, Cambridge, MA, 02138, USA. *email: gabriela.sobral@smns-bw.de
} 

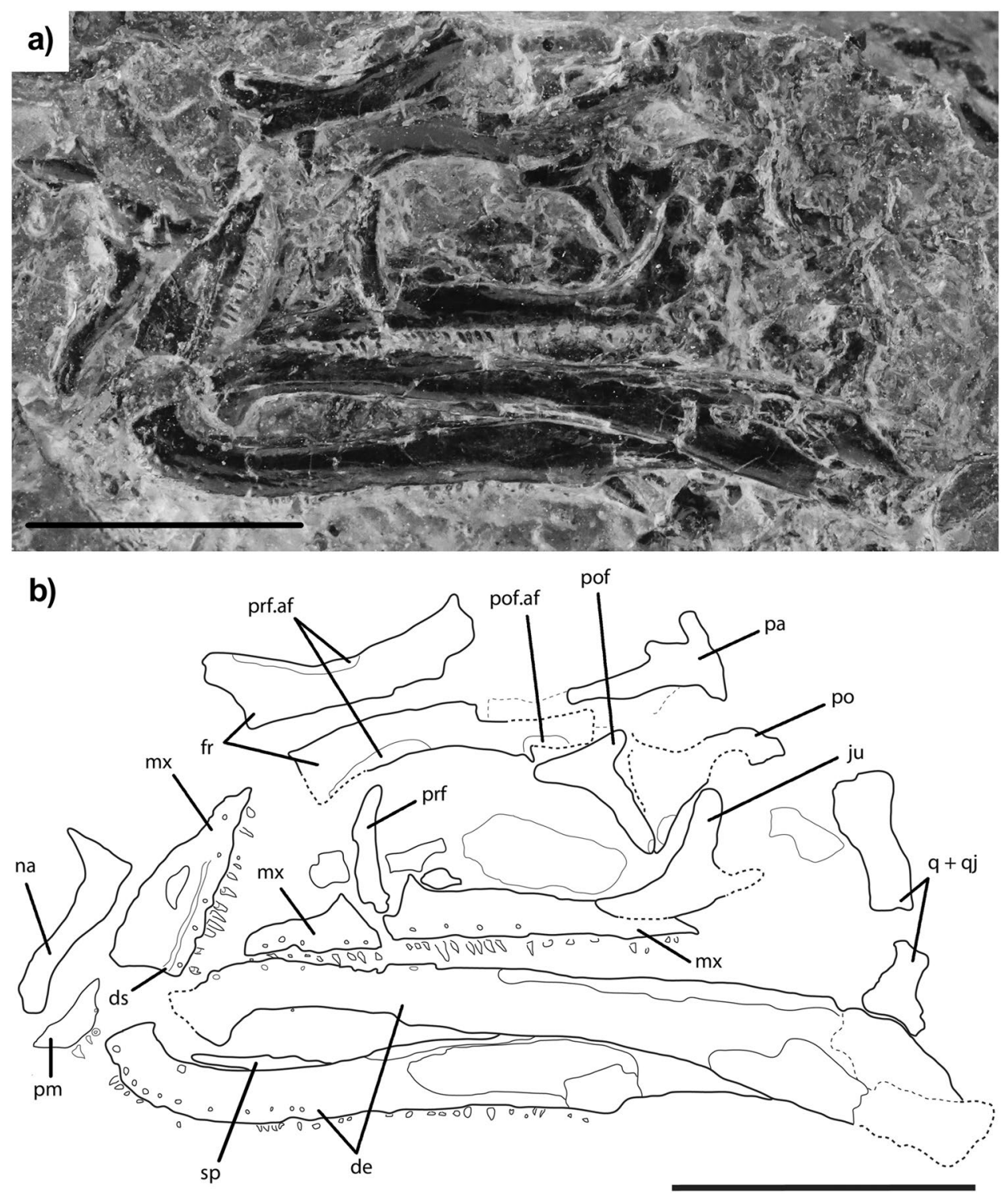

Figure 1. Picture (a) and line drawing (b) of the holotype material of Vellbergia bartholomaei. Scale bars approximately $5 \mathrm{~mm}$. Abbreviations: af articulation facet, de dentary, ds dental shelf, fr frontal, $\mathbf{m x}$ maxilla, na nasal, de dentary, ju jugal, pa parietal, pm premaxilla, po postorbital, pof postfrontal, prf prefrontal, q quadrate, qj quadratojugal, sp splenial.

the Czatkowice quarry in Poland (Early Triassic); the Vellberg locality in Germany (Middle Triassic); the Dont Formation in the Italian dolomites (Middle Triassic); the Lossiemouth Sandstone Formation in Northeast Scotland (Middle-Late Triassic); the Santa Maria Formation (Linha Bernardino locality) and Caturrita Formation (Linha São Luiz locality), in Southern Brazil (Late Triassic); and the Tytherington and Cromhall quarries in South

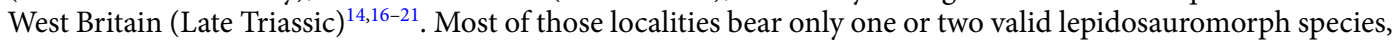
with the most speciose of those currently represented by the collection of quarries in Southwest Britain, which include remains from six rhynchocephalian species: Diphydontosaurus avonis, Planocephalosaurus robinsonae, Clevosaurus hudsoni, Clevosaurus minor, Clevosaurus cambrica, Clevosaurus sectumsemper ${ }^{22-26}$. Therefore, most of the early fossil record of lepidosauromorphs remains largely unknown.

Here, we report a new partially articulated fossil lepidosauromorph from the Middle Triassic deposits of Vellberg in Southern Germany. The new species described here falls into the smallest size cluster so far collected from the site, and likely represents the first juvenile individual from that locality. This new taxon depicts a mosaic of features that are generally observed in both early evolving rhynchocephalians and squamates, suggesting stem-lepidosauromorphs may have survived up to the Middle Triassic. It further demonstrates a more complex scenario on dental evolutionary patterns among early lepidosaurs. Finally, this and other findings from Vellberg indicate this is one of the richest sites in the world to understand early lepidosauromorph evolution. Together 

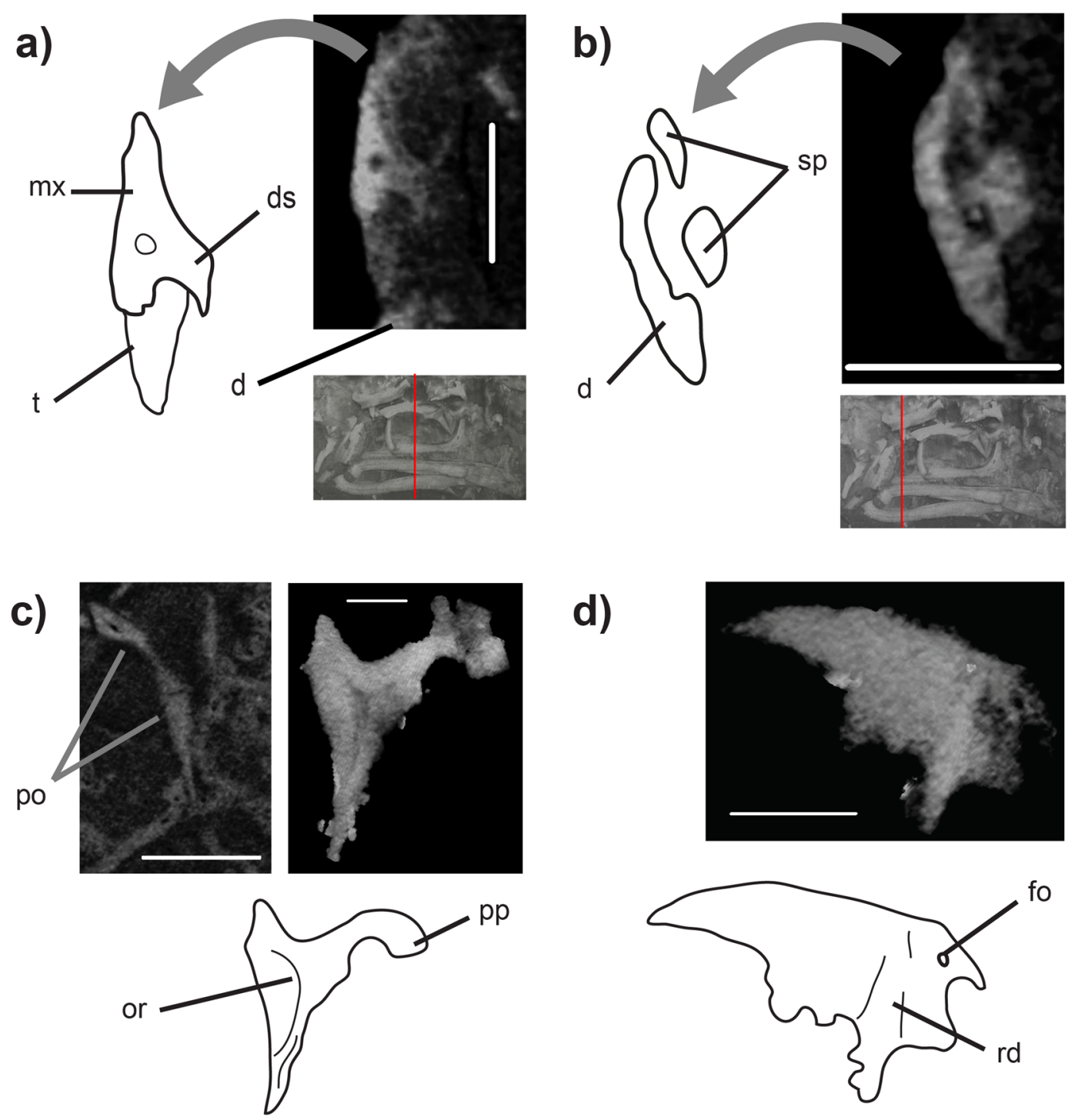

d)

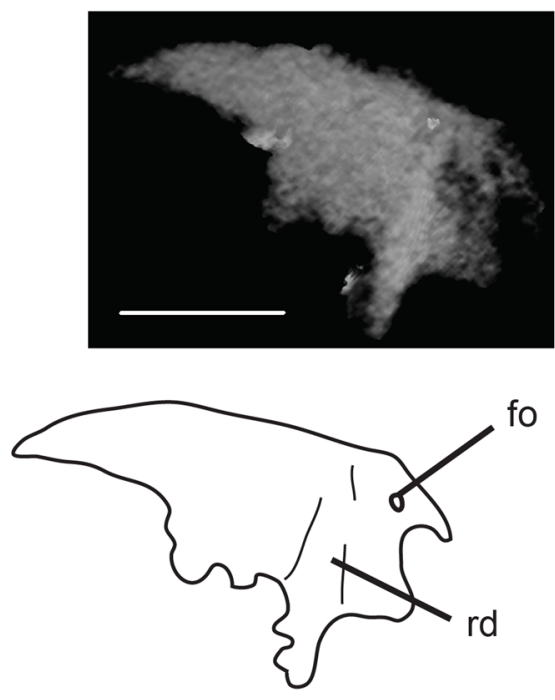

Figure 2. CT images of Vellbergia. Cross section trough (a) the left maxilla and (b) right dentary with grey miniatures below showing position of the slices. 3D renderings of the (c) postorbital (with CT slice) and (d) squamosal. Scale bars: (a and b) $0.7 \mathrm{~mm},(\mathbf{c}) 1.5 \mathrm{~mm}$ and $0.7 \mathrm{~mm},(\mathbf{d}) 0.95 \mathrm{~mm}$. Abbreviations: d dentary, ds dental shelf, fo foramen, or orbital rim, pp posterior process, $\mathbf{r d}$ ridge, $\mathbf{s p}$ splenial, $\mathbf{t}$ tooth.

with other taxa from this locality, Vellberg may also hold fundamental clues to understand the evolution of body size subsequent to the Permian-Triassic mass extinction.

\section{Results}

Systematic palaeontology

Lepidosauromorpha Gauthier, 1984

Vellbergia n. g.

Vellbergia bartholomaei $\mathrm{n}$. sp. (Figs. 1, 2, S1-S5)

Type: SMNS 91590, an approximately $12.5 \mathrm{~mm}$ long partial skull exposed in left-lateral view (Figs. 1-3; S1-S4). Type locality: Schumann limestone quarry, Vellberg (Eschenau), Germany

Type horizon: Grey mudstone bed \#6 (Schoch, 2002), Untere Graue Mergel, Lower Keuper, Middle Triassic (Ladinian).

Etymology: Vellbergia is named after the type locality; species name honoring Alfred Bartholomä of Neuenstein, who collected for many years in the Middle Triassic of Germany and donated much valuable material to public collections.

Diagnosis: Vellbergia bartholomaei is distinct from other lepidosauromorphs, including Fraxinisaura, by the following combination of features: symphysis strongly turned medially, T-shaped postfrontal, frontal with distinct antero-lateral and large postero-lateral processes; prefrontal dorsoventrally deep and not expanded 
a)

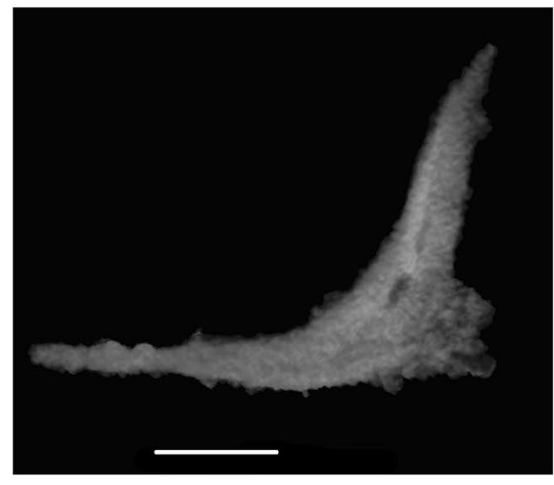

b)

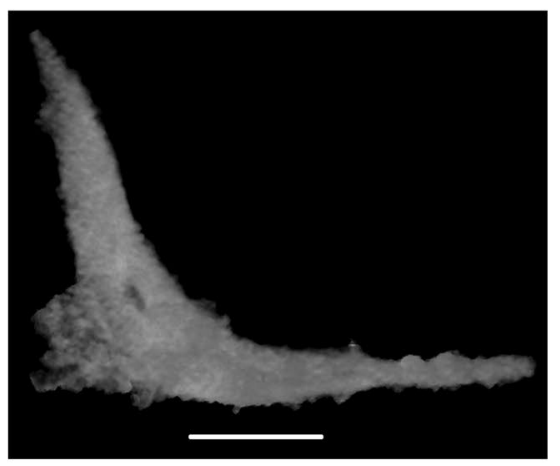

c)

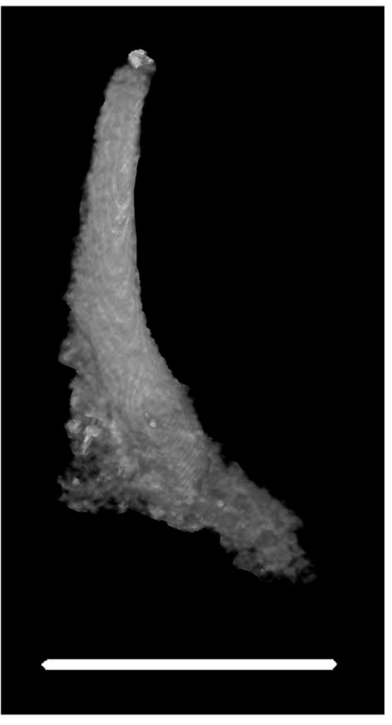

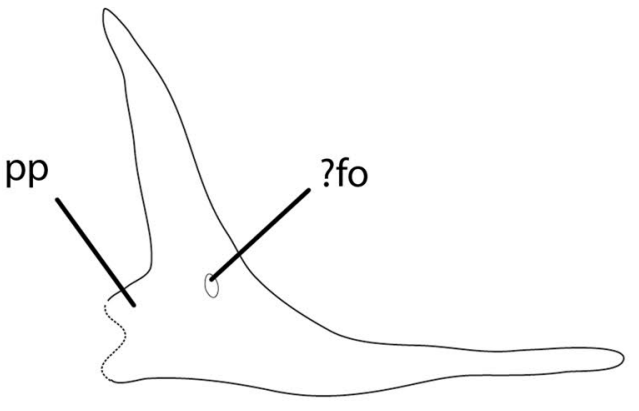

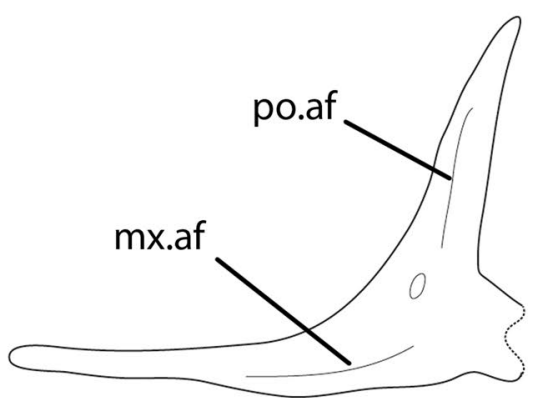

d)
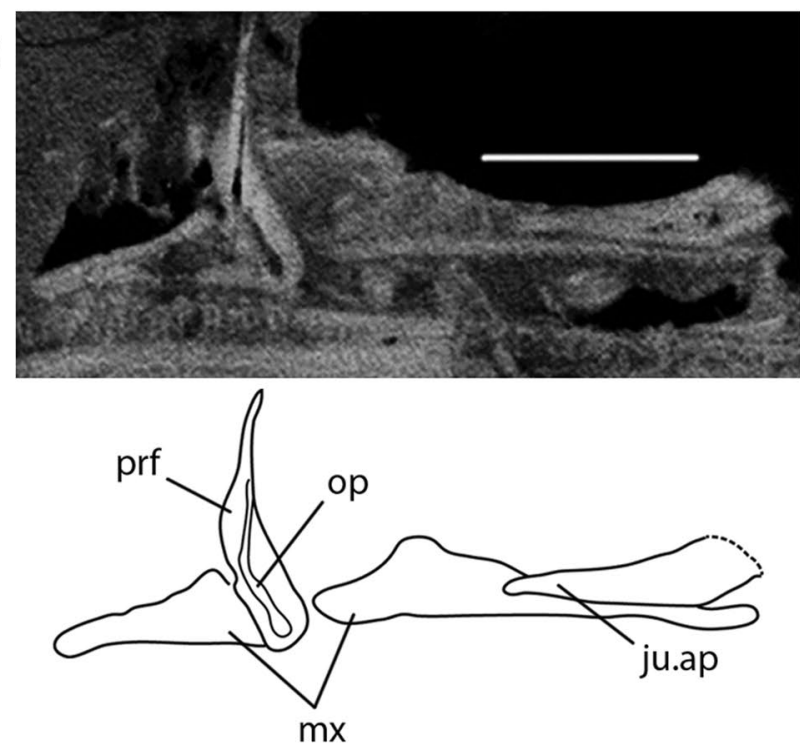

Figure 3. More details of Vellbergia. (a) Lateral and (b) medial views of the three-dimensional rendering (left) of the jugal and their corresponding line drawings (right), (c) left prefrontal with excess matrix removed (original segmentation in Fig. S2), and (d) CT scan (above) and line drawing (below) showing the relative positions of the prefrontal and the upper jaw. Scale bars: (a and b) $0.95 \mathrm{~mm}$, (c) $2 \mathrm{~mm}$, and (d) $2.5 \mathrm{~mm}$. Abbreviations: af articular facet, ap anterior process, fo foramen, ju jugal, $\mathbf{m x}$ maxilla, op opening, po postorbital, pp posterior process, prf prefrontal.

anteriorly; small and narrow teeth, maxillary tooth row extending to posterior rim of the orbit. See Supplementary Information for full anatomical description.

\section{Discussion}

Features of Vellbergia, such as the presence of well-developed subolfactory processes of the frontal, the presence of a ventrolateral process of the nasal, posterior teeth located apicolingually, and narrow, slender and short teeth relative to the lower jaw (Figs. 1-3; S1-S4), make Vellbergia distinct from other known lepidosauromorphs from the same locality, such as Fraxinisaura ${ }^{27}$ and a lower jaw previously attributed to $c f$. Diphydontosaurus ${ }^{15}$. Additionally, 


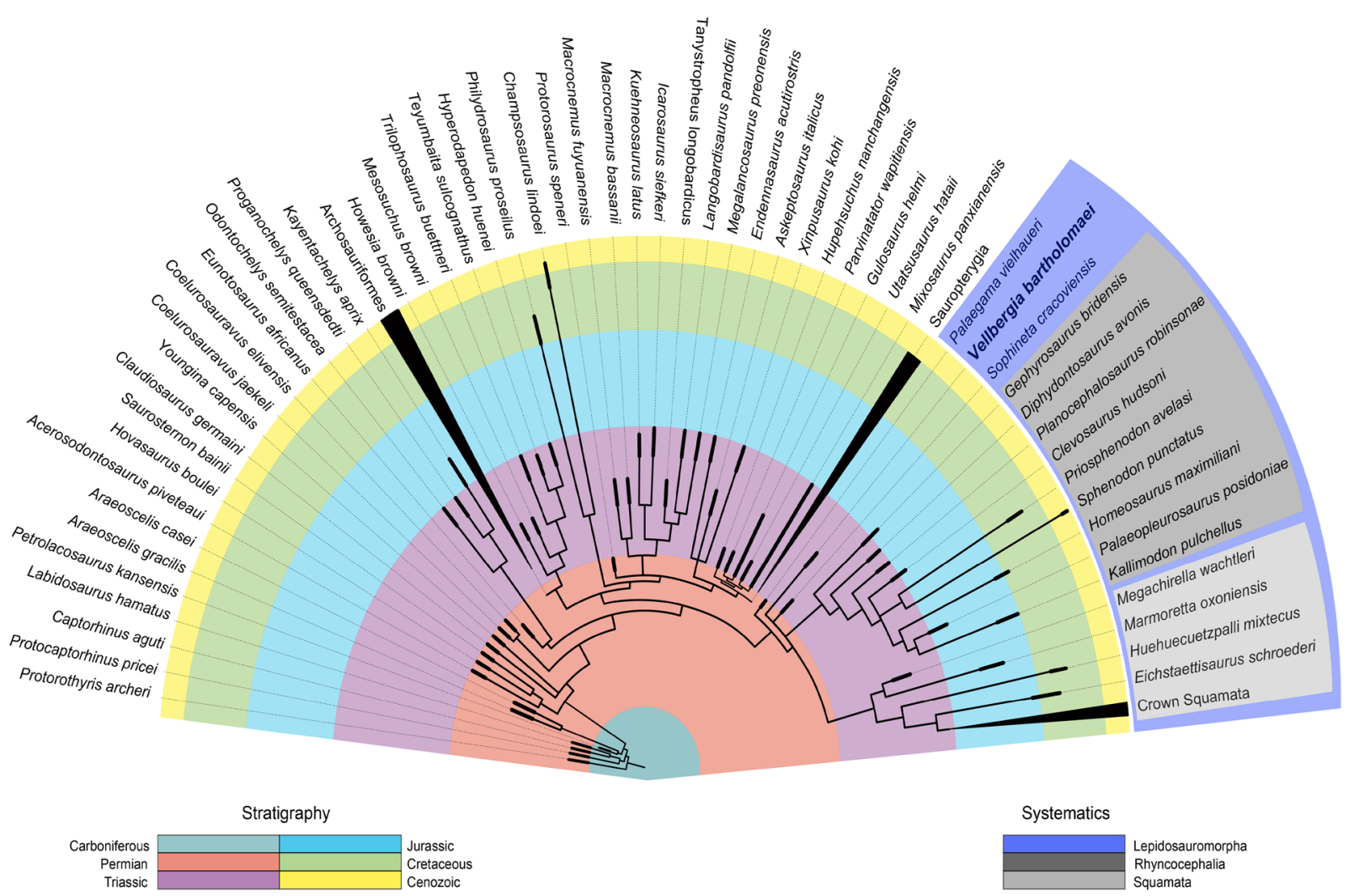

Figure 4. Time-scaled phylogeny depicting the relationships of Vellbergia based on the combined analysis of morphological and molecular data using Bayesian inference. Node positions do not reflect exact divergence times; branch lengths not to scale.

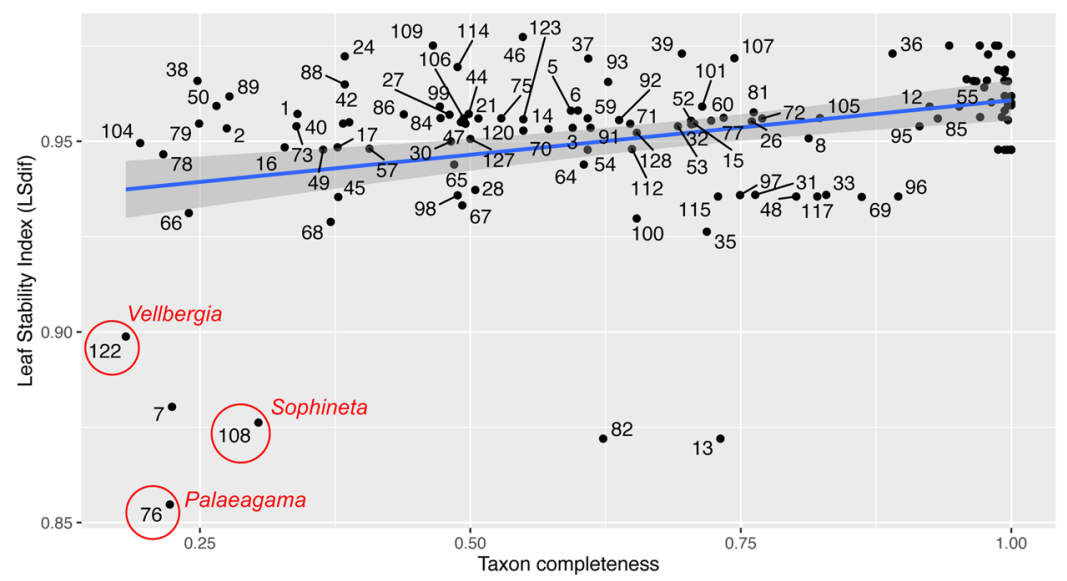

Figure 5. Taxon stability plotted against taxon completeness based on the posterior trees obtained from the Bayesian inference analysis. All taxa are identified in Table 1 below. Regression line in blue and 95\% confidence interval in grey. Labels for extant taxa ( $100 \%$ completeness) are omitted for simplicity.

the relatively large size of the orbit in relation to the rest of the skull, and the overall diminutive size of the skull, suggest Vellbergia was not a fully grown individual. However, we disregard it as a hatchling or a young juvenile by the high degree of ossification of cranial bones like frontals and nasals. Unless Vellbergia had exceptionally high growth rates, even adults of this species would have comprised one of the smallest tetrapods found in the Middle Triassic fauna from Vellberg.

In all our phylogenetic analyses, Vellbergia is recovered as a stem-lepidosauromorph (Figs. 4, and S7-S10). Using equal-weights maximum parsimony (EWMP), Bayesian inference (BI) with morphological data only, and BI with combined morphological and molecular data, Vellbergia is recovered in a polytomy with Sophineta ${ }^{28}$, rhynchocephalians, and squamates (Figs. 4, and S7, S9, S10). Maximum parsimony analysis with implied weighting 
(IWMP) (Fig. S8), also indicates Vellbergia it is a stem-lepidosauromorph, and a sister taxon to crown lepidosauromorphs (=Lepidosauria: Squamata + Rhynchocephalia), with Sophineta recovered as a stem-squamate. Palaeagama, as in previous analyses of this data set $^{2}$, does not have a strong negative impact on tree resolution, but behaves as a rogue taxon among different analysis (Fig. 5). Whereas in parsimony-based analyses Palaeagama is recovered on the lineage leading to archosauriforms, in BI analyses it falls in the polytomy at the base of Lepidosauromorpha (BI-morphology only), or as the earliest evolving stem-lepidosauromorph (BI-combined data).

Overall, our results indicate Vellbergia is a stem-lepidosauromorph outside Rhynchocephalia and Squamata, with uncertain affinities relative to the latter two clades and Sophineta. Importantly, despite the holotype of Vellbergia being less complete than other putative early evolving lepidosauromorphs (i.e. Sophineta and Palaeagama), it is more stable in its phylogenetic placement than those other candidate stem-lepidosauromorphs (Fig. 5). Yet, given its incompleteness and the consequent reduced stability of Vellbergia relative to other taxa among the Bayesian posterior trees (reflected on its overall low leaf stability), we prefer to take a conservative approach and consider Vellbergia as a putative stem-lepidosauromorph pending the recovery of additional material.

Important morphological attributes of Vellbergia, most notably the elongate and slender jaw bones, the deeper post-dentary region of the jaw relative to the anterior region, and the far posteriorly reaching maxillary tooth row can be found on some other early diverging diapsid species, such as Prolacerta and Youngina ${ }^{29,30}$, thus showing these features were retained into the early part of the lepidosauromorph evolutionary history as well. The postorbital is found partially, and the squamosal completely, within the matrix (Fig. 2c,d). The former is typically diapsid, while the latter is very similar to Diphydontosaurus ${ }^{24}$. The jugal has a posterior process, although its full length cannot be estimated because it is incomplete (Fig. 3a,b). The prefrontal is also incomplete, lacking the anterior extension as suggested by the articular facets on the frontals (Fig. 1). The prefrontal is a ventrally elongated bone that forms the entire anterior border of the orbit. Additionally, the ventralmost portion of the prefrontal is hidden within the matrix, behind the maxilla (Fig. 3c,d). Such dorsoventrally expanded prefrontal is commonly observed among rhynchocephalians due to the absence of the lacrimal in most of those taxa, suggesting that the lacrimal was possibly absent in Vellbergia (but which we cannot confirm at the present).

Most importantly, however, is the contribution of the anatomical features of Vellbergia to our understanding of the early evolution of lepidosauromorphs. For instance, the strongly recurved symphysis of the lower jaw (Figs. 1, S1, S2, S4) is remarkably similar to early diverging rhynchocephalians, such as Gephyrosaurus ${ }^{31}$ and Diphydontosaurus ${ }^{24}$ (TRS, pers. obs.; Figs. S5, S6). Also, the dentition in Vellbergia has an apicolingual placement on the jaw (Fig. 2a), which is somewhat intermediate to the condition observed in the posterior teeth of Gephyrosaurus and Diphydontosaurus (resembling some of the intermediate dentary teeth in Diphydontosaurus). However, Vellbergia still retains a splenial bone (Figs. 1, 2b, S4), by which it differs from all known rhynchocephalians. Such mosaic of early lepidosaurian features provides support for its placement as a stem-lepidosauromorph and may imply a more complex evolutionary scenario for the acquisition of acrodonty in early lepidosaurs-i.e. implying the acquisition of some level of acrodonty (i.e. at least part of the dental tissue being located on the apex of the labial wall of the jaw bone $\mathrm{e}^{32-34}$ ) outside rhynchocephalians among Triassic lepidosaurs. Cases of even partial development of the acrodont condition are extremely rare in non-lepidosauromorph reptiles $^{33}$, such as in the captorhinid Opisthodontosaurus ${ }^{32}$. However, the evolution of acrodonty or pleuroacrodonty (respectively, total or partial placement of the dental tissue on the apex of the jawbone) has occurred at least five independent times in lepidosauromorphs: in sphenodontians, priscagamids, acrodontans, borioteiioids, and trogonophid amphisbaenians ${ }^{33-36}$. Vellbergia thus demonstrates that this important dental character, which is conspicuous and diagnostic for some lepidosaur lineages (e.g. sphenodontians and acrodontans in particular), was already undergoing homoplastic evolution on the earliest stages of lepidosaur evolution.

The currently available data indicate that Vellbergia is geologically younger than other stem-lepidosauromorphs found to date, such as Sophineta (Early Triassic) and Palaeagama (Late Permian), although the latter has less phylogenetic stability and it is sometimes recovered as more closely related to other diapsid lineages ${ }^{2}$ (Figs. S7, S8). With the recent phylogenetic recharacterization of Marmoretta (Middle Jurassic of Britain) as a stem-squamate in the most comprehensive diapsid/lepidosaur data set available to date ${ }^{2}$ (and herein), Vellbergia represents the youngest record of an early evolving lepidosauromorph. It also indicates that stem-lepidosauromorphs (Vellbergia), rhynchocephalians ${ }^{15}$ and stem-squamates ${ }^{2}$ occurred across islands that, today, correspond to central Europe during the Middle Triassic, with at least stem-lepidosauromorphs and rhynchocephalians cohabiting what is today South Germany.

Recent excavations in the upper Middle Triassic of Germany have revealed a plethora of new taxa, most of which comprehend small-bodied forms when compared to other tetrapod-bearing basins of this time frame. These are the deposits of Kupferzell and Vellberg, which have produced new temnospondyls ${ }^{37,38}$, chroniosuchians $^{39}$, and a wide range of amniotes ${ }^{17,40}$. Apart from some enigmatic taxa ${ }^{17}$, the amniote fauna is dominated by diapsids, among which there are archosauriforms ${ }^{17}$, a putative choristodere, stem-turtles ${ }^{5,41}$ and also early evolving rhynchocephalians ${ }^{15}$ and one putative stem-lepidosauromorph ${ }^{27}$ - the latter currently undergoing systematic revision. In addition to the new taxon described here and the two previously recognized lepidosauromorph species from Vellberg, two other undescribed lepidosauromorphs are known from the site (GS, RRS, in prep.), making the Vellberg locality to rival the lepidosauromorph diversity from the Late Triassic of Southwest Britain. Further, considering the higher frequency of articulated or partially articulated specimens from Vellberg (thus differing from the Polish and British Triassic localities), and its considerably older age in relation to the British deposits, we consider that the Vellberg locality represents one of the most important Triassic sites towards understanding the early evolution of lepidosauromorphs.

Besides the good representation of lepidosauromorphs, Vellberg is characterized by a large number of tetrapod fossils of small body size. Among reptiles, most species currently known for this locality are no longer than 
$40 \mathrm{~mm}$ in jaw length, even among archosauriforms (Sues et al.; in rev.). The exceptions are the archosauriform Jaxtasuschus ( $~ 80 \mathrm{~mm}$ skull length) and two large pseudosuchians (Batrachotomus and an unnamed taxon). The frequent appearance of small body sizes contrasts with younger Triassic deposits, in which different tetrapod body size classes are considerably better represented. They vary from small reptiles (e.g. lepidosaurs, parareptiles and cynodonts) with $20-50 \mathrm{~mm}$ in mandible/head length to archosaurs with mandible/head length and estimated body mass 10-15 times longer/larger, such as in the Santa Maria and Caturrita formations in Southern Brazil (Ladinian-Norian), Ischigualasto Formation in Northwest Argentina (Carnian-Norian), the Chinle Formation in the Southwest USA (Carnian-Rhaetian), among others ${ }^{42-45}$. A high representation of small-bodied faunal assemblages is more frequently observed in Triassic localities that are older than Vellberg, from Induan to the Anisian/ Ladinian (first $\sim 7-10 \mathrm{Myr}$ in the Triassic). The Lilliput effect is a suggested phenomenon in which animals of small body sizes had higher rates of survival following the end-Permian, especially in lower latitudes. Smaller body sizes are capable of better heat exchange, thus providing a functional advantage during periods of fast climatic change, like the global warming around the Permian-Triassic mass extinction ${ }^{9,46,47}$. Such higher representation of small-bodied taxa after the Permian-Triassic mass extinction was first identified for marine invertebrates, but it has also been found more recently in terrestrial vertebrate faunas, such as in Early Triassic deposits in Russia, South Africa and Poland ${ }^{16,46,47}$. The low availability of Early and early Middle Triassic terrestrial deposits worldwide bearing tetrapod remains limits the assessment of body size class transitions over time. However, the location of Vellberg at a low latitude during the Ladinian $\left(27^{\circ} \mathrm{N}\right)^{48}$, especially when compared to other known, higher-latitude contemporary localities (eg.: Santa Maria Formation, Brazil, ca. $45^{\circ} \mathrm{S}$ ), may suggest that some low latitude localities still had a predominantly small bodied fauna by the middle Ladinian (240 Mya, or $12 \mathrm{Myr}$ after the Permian-Triassic extinction), and thus a longer lasting influence of the Lilliput effect.

The observed small-bodied predominance remains to be confidently demonstrated and could, however, indicate a collecting bias instead. Small-bodied fossils require special search strategies. Since these efforts are not as commonly deployed as techniques more suitable for macrofossils, recovery of small body size diapsids is usually a by-product of finding other, more frequently targeted groups, such as archosaurs ${ }^{49}$. This could create a bias towards larger body sizes being sampled in most Middle to Late Triassic deposits (although this cannot explain the absence of, theoretically easier to find, large-bodied taxa in earlier Triassic strata). In any case, be it natural or human biased, concentrating collection efforts in these areas will reveal more details on the early evolution of lepidosauromorphs and other diapsid reptiles. Present-day vertebrate diversity is considerable among small-bodied animals ${ }^{49}$, such as lepidosaurs ${ }^{11}$. However, size-class bias in fossil sampling efforts, and preservation potential, currently pose as important limitations towards accurately assessing small-bodied vertebrates diversity ${ }^{50}$. The exploration of small-bodied vertebrates in Vellberg has already provided fundamental data towards understanding key points in the early radiation of diapsid reptiles, thus indicating we may be missing important parts of the reptile evolution by overlooking small size class materials.

\section{Methods}

Specimen availability. The holotype and only specimen of the new taxon is housed in the Staatliches Museum für Naturkunde Stuttgart, Germany under the number SMNS 91590. The anatomical analysis was made with the aid of computed-tomography (CT) scans performed with a Metrotom 800 Generation 1 scanner (S. Tomaschko Zeiss Computertomographie Dienstleistung, Essingen, Germany) using $110 \mathrm{kV}$ and $265 \mu \mathrm{A}$ at $500 \mathrm{~ms}$ and a voxel size of $17,94 \mu \mathrm{m}$. Segmentations and measurements were made in the software VG Studio Max 2.0 (Volume Graphics, Heidelberg, Germany). A complete anatomical description is provided in the Supplementary Material.

Morphological and molecular data sets. In order to assess the phylogenetic placement of Vellbergia bartholomaei among diapsid reptiles, we included it in the recently published phylogenetic data matrix of Simões et al. ${ }^{2}$. This data set includes the largest taxonomic sampling available for early diapsid reptiles, and also includes considerable revisions on the construction of morphological characters based on discussions provided by ${ }^{51,52}$. This data set contains both a morphological and a molecular partition sampled for all of the extant taxa included in the data set. Owing to the beneficial effect of removing rogue taxa in phylogenetic analysis, especially in the gain in resolution in support ${ }^{53}$, we removed two taxa that operate as wildcards in the previous version of this data set (Paliguana $^{12,13}$ and Pamelina ${ }^{54}$ ) [Simões et al. ${ }^{2}$, Extended Data Fig. 9]. Not all taxa identified as wildcards were removed (e.g. Palaeagama ${ }^{12,13}$ and Sophinet ${ }^{28}$ ), in order to find a balance between increase in tree resolution and support versus keeping a taxonomic sampling relevant to the questions addressed in the present study. Our results consist of morphology only, as well as morphological and molecular (combined evidence) analyses.

Parsimony analysis. Analyses are conducted in TNT v. $1.1^{55}$ using the New Technology Search (NTS) algorithms. Tree searches are conducted using 1,000 initial trees by random addition sequences (RAS) with 100 iterations/round for each of the four NTS algorithms: Sectorial Search, Ratchet, Drift and Tree Fusing. The output trees are used as the starting trees for subsequent runs, using 1,000 iterations/rounds of each of the NTS algorithms. The latter step is repeated once again, and the final output trees are filtered for all the most parsimonious trees (MPTs).

Bayesian inference analyses. Analyses are conducted using Mr. Bayes v. 3.2.6 $6^{56}$. As there are no changes to the molecular data set we used ${ }^{2}$, molecular partitions and models of evolution are the same as that study. The morphological partition is analysed with the Mkv model (given that autapomorphies are included in the data set, but there are no invariable characters). Rate variation across characters is sampled from a gamma distribution, and analyses used 4 independent runs with 6 Markov chains each, sampling at every 1000 generations, for a total of 50 million generations. Convergence of independent runs is assessed using: average standard deviation of split 
frequencies (ASDSF $\sim 0.01$ ), potential scale reduction factors (PSRF $\approx 1$ for all parameters) and effective sample size (ESS) for each parameter is greater than 200.

Leaf stability analysis. Leaf stability was assessed using RogueNaRok ${ }^{53}$, which allows assessing the difference between the highest and the second highest support values for alternative resolutions of each taxon quartet/ triplet in the data set (LSdif) ${ }^{57}$. We applied this method to the posterior trees from the Bayesian inference analysis including both morphological and molecular data. Because of the large number of taxa and large number of trees, it was necessary to downsample the total number of posterior trees from each analysis $(100,000$ trees after discarding burn-in). The final sample consisted of 10,000 trees (selecting one at every 10 trees) using the Burntrees script for Perl $^{58}$.

\section{Data availability}

The CT data of Vellbergia barthomolaei, as well as the data matrix used in the phylogenetic analyses can be accessed on Dryad under the following address: https://doi.org/10.5061/dryad.d2547d7zs.

Received: 27 November 2019; Accepted: 22 January 2020;

Published online: 20 February 2020

\section{References}

1. Irisarri, I. et al. Phylotranscriptomic consolidation of the jawed vertebrate timetree. Nature Ecology \& Evolution (2017).

2. Simões, T. R. et al. The origin of squamates revealed by a Middle Triassic lizard from the Italian Alps. Nature 557, 706-709 (2018).

3. Sobral, G., Sues, H.-D. \& Müller, J. Anatomy of the enigmatic reptile Elachistosuchus huenei janensch, 1949 (Reptilia: Diapsida) from the Upper Triassic of Germany and its relevance for the origin of Sauria. PLoS ONE 10, e0135114 (2015).

4. Ezcurra, M. D., Scheyer, T. M. \& Butler, R. J. The origin and early evolution of Sauria: Reassessing the permian saurian fossil record and the timing of the crocodile-lizard divergence. PLOS ONE 9, e89165 (2014).

5. Schoch, R. R. \& Sues, H.-D. A Middle Triassic stem-turtle and the evolution of the turtle body plan. Nature 523, 584-587 (2015).

6. Scheyer, T. M. et al. A new, exceptionally preserved juvenile specimen of Eusaurosphargis dalsassoi (Diapsida) and implications for Mesozoic marine diapsid phylogeny. Sci. Rep. 7, 4406 (2017).

7. Ji, C. et al. Phylogeny of the Ichthyopterygia incorporating recent discoveries from South China. J. Vert. Paleontol. 36, e1025956 (2016).

8. Chen, Z.-Q. \& Benton, M. J. The timing and pattern of biotic recovery following the end-Permian mass extinction. Nat. Geosc. 5, 375-383 (2012)

9. Erwin, D. H. Extinction-How Life on Earth Nearly Ended 250 Million Years Ago. Updated Edition. 320 (Princeton University Press, 2015).

10. Pincheira-Donoso, D., Bauer, A. M., Meiri, S. \& Uetz, P. Global taxonomic diversity of living reptiles. PLoS One 8, e59741 (2013).

11. Uetz, P. \& Hošek, J. The Reptile Database, http://www.reptile-database.org (2019).

12. Carroll, R. L. Permo-Triassic 'lizards' from the Karroo. Palaeontol. Afr. 18, 71-87 (1975),

13. Carroll, R. L. In Problems in Vertebrate Evolution Vol. 4 (eds. Andrews, S. M. Miles, R. S. \& Walker, A. D.) 1-28 (Academic Press, 1977).

14. Hsiou, A. S. et al. A new clevosaurid from the Triassic (Carnian) of Brazil and the rise of sphenodontians in Gondwana. Sci. Rep. 9, $11821(2019)$

15. Jones, M. E. H. et al. Integration of molecules and new fossils supports a Triassic origin for Lepidosauria (lizards, snakes, and tuatara). BMC Evol. Biol. 13 (2013).

16. Borsuk-Białynicka, M., Cook, E., Evans, S. E. \& Maryanska, T. A microvertebrate assemblage from the Early Triassic of Poland. Acta Palaeontol. Pol. 44, 167-188 (1999).

17. Schoch, R. R. \& Seegis, D. A Middle Triassic palaeontological gold mine: the vertebrate deposits of Vellberg (Germany). Palaeogeogr., Palaeoclimatol., Palaeoecol. 459, 249-267 (2016).

18. Fraser, N. C. In In the Shadow of the Dinosaurs: Early Mesozoic Tetrapods (eds. Fraser, N. C. \& Sues, H. D.) 214-226 (Cambridge University Press, 1994).

19. Hsiou, A. S., De França, M. A. G. \& Ferigolo, J. New data on the Clevosaurus (Sphenodontia: Clevosauridae) from the Upper Triassic of Southern Brazil. PLoS ONE 10, e0137523 (2015).

20. Fraser, N. C. \& Benton, M. J. The Triassic reptiles Brachyrhinodon and Polysphenodon and the relationships of the sphenodontids. Zool. J. Linn. Soc. 96, 413-445 (1989).

21. Bonaparte, J. F., Schultz, C. L., Soares, M. B. \& Martinelli, A. G. La fauna local de Faxinal do Soturno, Triásico Tardío de Rio Grande do Sul, Brasil. Rev. Bras. Paleontol. 13, 233-246 (2010).

22. Fraser, N. C. The osteology and relationships of Clevosaurus (Reptilia: Sphenodontida). Philos. Trans. R. Soc. Lond., Ser. B: Biol. Sci. 321, 125-178 (1988).

23. Fraser, N. C. A new rhynchocephalian from the British Upper Trias. Palaeontology 25, 709-725 (1982).

24. Whiteside, D. I. The head skeleton of the Rhaetian sphenodontid Diphydontosaurus avonis gen. et sp. nov. and the modernizing of a living fossil. Philos. Trans. R. Soc. Lond., Ser. B: Biol. Sci. 312, 379-430 (1986).

25. Chambi-Trowell, S. A. V., Whiteside, D. I. \& Benton, M. J. Diversity in rhynchocephalian Clevosaurus skulls based on CT reconstruction of two Late Triassic species from Great Britain. Acta Palaeontol. Pol. 64, https://doi.org/10.4202/app.00569.02018 (2019).

26. Klein, C. G., Whiteside, D. I., de Lucas, V. S., Viegas, P. A. \& Benton, M. J. A distinctive Late Triassic microvertebrate fissure fauna and a new species of Clevosaurus (Lepidosauria: Rhynchocephalia) from Woodleaze Quarry, Gloucestershire, UK. Proc. Geol. Assoc. 126, 402-416 (2015).

27. Schoch, R. R. \& Sues, H.-D. A new lepidosauromorph reptile from the Middle Triassic (Ladinian) of Germany and its phylogenetic relationships. J. Vert. Paleontol. 38, e1444619 (2018).

28. Evans, S. E. \& Borsuk-Białynicka, M. A small lepidosauromorph reptile from the Early Triassic of Poland. Palaeontol. Pol. 65, 179-202 (2009).

29. Gow, C. E. The morphology and relationships of Youngina capensis Broom and Prolacerta broomi Parrington. Palaeontol. Afr. 18, 89-131 (1975).

30. Modesto, S. P. \& Sues, H.-D. The skull of the Early Triassic archosauromorph reptile Prolacerta broomi and its phylogenetic significance. Zool. J. Linn. Soc. 140, 335-351 (2004).

31. Evans, S. E. The skull of a new eosuchian reptile from the Lower Jurassic of South Wales. Zool. J. Linn. Soc. 70, 203-264 (1980).

32. Haridy, Y., LeBlanc, A. R. H. \& Reisz, R. R. The Permian reptile Opisthodontosaurus carrolli: a model for acrodont tooth replacement and dental ontogeny. J. Anat. 232, 371-382 (2018).

33. Bertin, T. J., Thivichon-Prince, B., LeBlanc, A. R., Caldwell, M. W. \& Viriot, L. Current perspectives on tooth implantation, attachment, and replacement in Amniota. Frontiers in Physiology 9 (2018). 
34. Simões, T. R., Wilner, E., Caldwell, M. W., Weinschütz, L. C. \& Kellner, A. W. A. A stem acrodontan lizard in the Cretaceous of Brazil revises early lizard evolution in Gondwana. Nat. Comm. 6, 9149 (2015).

35. Borsuk-Białynicka, M. The Late Cretaceous lizard Pleurodontagama and the origin of tooth permanency in Lepidosauria. Acta Palaeontol. Pol. 41, 231-252 (1996).

36. Chavarría-Arellano, M. L., Simões, T. R. \& Montellano-Ballesteros, M. New data on the Late Cretaceous lizard Dicothodon bajaensis (Squamata, Borioteiioidea) from Baja California, Mexico reveals an unusual tooth replacement pattern in squamates. An. Acad. Bras. Cienc. 90, 2781-2795 (2018).

37. Schoch, R. R. A complete trematosaurid amphibian from the Middle Triassic of Germany. J. Vert. Paleontol. 26, 29-43 (2006).

38. Schoch, R. R. A new stereospondyl from the German Middle Triassic, and the origin of the Metoposauridae. Zool. J. Linn. Soc. 152, 79-113 (2008).

39. Witzmann, F., Schoch, R. \& Maisch, M. A relic basal tetrapod from the Middle Triassic of Germany. Naturwissenschaften 95, 67-72 (2008).

40. Schoch, R. R. Stratigraphie und Taphonomie wirbeltierreicher Schichten im Unterkeuper (Mitteltrias) von Vellberg (SW-Deutschland). (na, 2002).

41. Schoch, R. R. \& Sues, H.-D. Osteology of the Middle Triassic stem-turtle Pappochelys rosinae and the early evolution of the turtle skeleton. J. Syst. Palaeont., Online first: https://doi.org/10.1080/14772019.14772017.11354936 (2017).

42. Barberena, M., Holz, M., Schultz, C. \& Scherer, C. In Sítios Paleontológicos do Brasil (ed. C.; Campos Schobbenhaus, D.A.; Queiroz, E.T.; Winge, M.) 11-22 (2002).

43. Langer, M. C., Ribeiro, A. M., Schultz, C. L. \& Ferigolo, J. In The Global Triassic Vol. 41 (eds. Spencer G Lucas \& Justin A Spielmann) 201-218 (New Mexico Museum of Natural History, 2007).

44. Irmis, R. B. The vertebrate fauna of the Upper Triassic Chinle Formation in northern Arizona. Mesa Southwest Mus Bull 9, 63-88 (2005).

45. Martínez, R. N. et al. Vertebrate succession in the Ischigualasto Formation. J. Vert. Paleontol. 32, 10-30 (2012).

46. Sun, Y. et al. Lethally Hot Temperatures During the Early Triassic Greenhouse. Science 338, 366-370 (2012).

47. Twitchett, R. J. The Lilliput effect in the aftermath of the end-Permian extinction event. Palaeogeogr., Palaeoclimatol., Palaeoecol. 252, 132-144 (2007).

48. Dercourt, J. et al. Atlas Peri-Tethys of Pelaeogeographical maps. (University of Pierre et Marie Curie, 2000).

49. Evans, S. E. At the feet of the dinosaurs: the early history and radiation of lizards. Biol. Rev. 78, 513-551 (2003).

50. Mitchell, J. S. Preservation is predictable: quantifying the effect of taphonomic biases on ecological disparity in birds. Paleobiology 41, 353-367 (2015).

51. Simões, T. R., Caldwell, M. W., Palci, A. \& Nydam, R. L. Giant taxon-character matrices: quality of character constructions remains critical regardless of size. Cladistics 33, 198-219 (2017).

52. Simões, T. R., Caldwell, M. W., Palci, A. \& Nydam, R. L. Giant taxon-character matrices II: a response to Laing et al. (2017). Cladistics 34, 702-707 (2018)

53. Aberer, A. J., Krompass, D. \& Stamatakis, A. Pruning rogue taxa improves phylogenetic accuracy: An efficient algorithm and webservice. Syst. Biol. 62, 162-166 (2013).

54. Evans, S. E. An early kuehneosaurid reptile from the Early Triassic of Poland. Palaeontologica Polonica 65, 145-178 (2009).

55. Goloboff, P. A., Farris, J. S. \& Nixon, K. C. TNT, a free program for phylogenetic analysis. Cladistics 24, 774-786 (2008).

56. Ronquist, F. et al. MrBayes 3.2: efficient Bayesian phylogenetic inference and model choice across a large model space. Syst. Biol. 61, 539-542 (2012).

57. Wilkinson, M. Identifying stable reference taxa for phylogenetic nomenclature. Zool. Scr. 35, 109-112 (2006).

58. Nylander, J. A. A. Burntrees, https://github.com/nylander/Burntrees (2014).

\section{Acknowledgements}

We are much indebted to Werner Kugler, Frank Ullmann, Brigitte Rozynek, and Traugott Haubold for help in the field. Isabell Rosin prepared the specimen and raised our attention to this find. We also thank the Schumann family for granting access to the site. The authors are thankful to Michael Caldwell (University of Alberta) and two anonymous reviewers for their thorough reviews on this manuscript (including the supplementary material). GS and RS thank the grant provided by the Deutsche Forschungsgemeinschaft, Award: 397562308. TRS thanks The Museum of Comparative Zoology, Harvard University for an Alexander Agassiz Postdoctoral Fellowship.

\section{Author contributions}

G.S. and T.R.S., performed taxonomic description, morphological comparisons, phylogenetic analyses and manuscript writing. R.R.S. conceptualized the project, contributed to anatomical interpretations, discussions and manuscript editing.

\section{Competing interests}

The authors declare no competing interests.

\section{Additional information}

Supplementary information is available for this paper at https://doi.org/10.1038/s41598-020-58883-x.

Correspondence and requests for materials should be addressed to G.S.

Reprints and permissions information is available at www.nature.com/reprints.

Publisher's note Springer Nature remains neutral with regard to jurisdictional claims in published maps and institutional affiliations.

Open Access This article is licensed under a Creative Commons Attribution 4.0 International License, which permits use, sharing, adaptation, distribution and reproduction in any medium or format, as long as you give appropriate credit to the original author(s) and the source, provide a link to the Creative Commons license, and indicate if changes were made. The images or other third party material in this article are included in the article's Creative Commons license, unless indicated otherwise in a credit line to the material. If material is not included in the article's Creative Commons license and your intended use is not permitted by statutory regulation or exceeds the permitted use, you will need to obtain permission directly from the copyright holder. To view a copy of this license, visit http://creativecommons.org/licenses/by/4.0/.

(C) The Author(s) 2020 